\title{
Using Petrophysical Properties of Volcanic Rocks in the Interpretation of Geophysical Data (Volcano Ebeko, Kuril Islands)
}

\author{
A. Ya. Shevko ${ }^{1}$, M. P. Gora ${ }^{1}$, N. A. Golikov ${ }^{2}$, G. L. Panin ${ }^{2}$, E. P. Bessonova ${ }^{3}$ \\ ${ }^{1}$ Siberian Branch of Russian Academy of Sciences, V S Sobolev Institute of Geology and Mineralogy, Novosibirsk, Russia \\ ${ }^{2}$ Siberian Branch of Russian Academy of Sciences, Trofimuk Institute of Petroleum Geology and Gejphysics, \\ Novosibirsk, Russia \\ ${ }^{3}$ Tomsk Polytechnic University, Russia \\ Email: sp@igm.nsc.ru
}

Received 2013

\begin{abstract}
Petrophysical properties of volcanic rocks were investigated on the North-Eastern fumarolic field of the volcano Ebeko. The attempt is made to use this data in order to interpret the geo-electrical cross sections of the fumarolic field subsurface space.
\end{abstract}

Keywords: Petrophysical Property; Electrical Resistivity; Electrical Tomogpaphy; Fumarolic Field; Volcano Ebeko; the Kuril Islands

\section{Introduction}

The study of thermal fields subsurface space on active volcanoes is only possible using non-destructive methods. This is due to the fact that any intervention (drilling, laying of test pits) entails a violation of the natural equilibrium of natural systems. The use of geophysical methods (electrical resistivity tomography) gives the possibility to reveal the inner structure of thermal fields and to identify the shapes of the underground reservoirs and feed channels [1]. The complex of petrophysical methods allows to fill physicochemical model of the volcano-hydrothermal system with real data $[2,3]$. In addition, the petrophysical properties of rocks can be used for the interpretation of the cross sections obtained by the electrical resistivity tomography method.

\section{Object of the Research}

Active volcano Ebeko is located in the Northern part of the island of Paramushir (Kuril Islands). At present the volcano keeps a high activity. It consists in periodic emissions of resurgent ashes, ongoing activities of fumaroles and hot springs [4,5]. Solutions of the boiling pools and hot springs on the fumarolic field are presented acid or hyper-acid waters ( $\mathrm{pH}$ values range from - 0.4 to 1.7). The temperatures of the thermal solutions range from $41^{\circ} \mathrm{C}$ to $92^{\circ} \mathrm{C}$. The mineralization range is from 2.7 to $20 \mathrm{~g} / \mathrm{L}$. The major anions of the solutions are chlorides and sulfates in different proportions and concentrations. The concentrations of chlorides vary from several fold to three orders of magnitude. The microelement concentrations also varied widely in the different thermal solutions [6].

The field samplings were carried out from different parts of the North-Eastern fumarolic field of the volcano Ebeko. The samples of unaltered and hydrothermally altered volcanic rocks were collected. Metasomatic alteration of volcanogenic rocks are represented by replacement phenocrysts and basis of the rocks by new growth minerals. Partial alteration plagioclase is the initial stage of metasomatism. In the further process of changes captures as porphyric crystals, so the groundmass of the volcanites with the formation of argillizated rocks.

\section{Analytical Methods}

Study of the petrophysical properties of the samples was performed according to standard and generally accepted method, modified taking into account the fact that part of the samples had a cavernous porosity. It was carried out the following analyses: porosity method of water saturation; the volume and mineral density; the absolute permeability to gas. Specific electric resistivity was measured by two techniques: resistivity with natural saturation and resistivity in artificial saturation of the solution with a concentration of $6 \mathrm{~g} / \mathrm{l}$ was determined by standard methods in atmospheric conditions; a change of resistiv- 
ity with increase of temperature up to $70^{\circ} \mathrm{C}$ was carried out at a facility for the simulation of the formation of conditions for effective pressure $8 \mathrm{M}$ Ia. All researches were performed in the laboratory of experimental seismology of IPGG of the SB RAS.

Eelectrical resistivity tomography of the volcano Ebeco North-Eastern fumarolic field was carried out on the equipment of the «Rock-48» using two cables, the total number of electrodes which was 48 . Step between the electrodes was equal to $5 \mathrm{~m}$. In this case a maximum spacing of the installation was about $235 \mathrm{~m}$ and maximum depth sensing was about $40 \mathrm{~m}$. A system of monitoring of Schlumberger was used in all cases. The profiles were oriented parallel to the slope to reduce the distortions caused by the influence of the relief [7].

\section{Results and Discussion}

Volcano Ebeco, according to our field investigation, consists mainly of flows andesites, less andesite-basalts and basalts. Thus, the samples in varying degrees altered andesites, selected on the North-Eastern fumarolic field, is the representative and may characterize the cross section structure of the thermal field. Some results of petrophysical studies of these rocks are given in the Table 1.

As you can see, tuff breccia has the minimum values electrical resistivity and maximum coefficients of porosity and permeability in comparison with the other surveyed rocks. The coefficient of the porosity of andesites varies from 10 to $27 \%$, and the permeability of the rocks by this is changed to 2 orders of magnitude (Figure 1). On the figures, in addition to the points corresponding to the characteristics of the volcano Ebeco rocks, for comparison are given points for the rocks of Golovnin volcano (Kunashir island, Kuril islands). Previously, we carried out a study of petrophysical properties in combination with petrological description of volcanic rocks of Golovnin caldera to compare basic parameters with texture-structural characteristics of rocks [8].

Table 1. Petrophysical property of the volcano Ebeko rocks.

\begin{tabular}{lcccc}
\hline Specimen & Rock & $\begin{array}{c}\text { Permeability } \\
\text { coefficient, } \\
\mathrm{mD}\end{array}$ & $\begin{array}{c}\text { Porosity } \\
\text { coefficient, } \\
\%\end{array}$ & $\begin{array}{c}\text { Electrical } \\
\text { resistivity, } \\
\text { om*m, 6 g/l }\end{array}$ \\
\hline PR-117 & Andesite & 1 & 22,2 & 57,1 \\
PR-118 & Andesite & 126 & 27,8 & 39,5 \\
PR-119 & Tuff breccia & 183 & 33,8 & 14,8 \\
PR-120 & Andesite & 1,22 & 18,3 & 27,7 \\
PR-121 & Andesite & 162 & 20,7 & 60,8 \\
PR-122 & Argillizated rock & 0,22 & 22,7 & 27,0 \\
PR-123 & Argillizated rock & 10,9 & 17,7 & 89,9 \\
PR-124 & Andesite & 1,18 & 22,7 & 63,1 \\
PR-125 & Andesite & 2,53 & 10,9 & 124,6 \\
\hline
\end{tabular}

It is established, that effusive and tuffaceous rocks form a discrete group on its petrophysical properties. [9]. According to our data, tuffs and tuff breccias are the most high porosity and permeability. Nevertheless properties as effusive rocks so and tufaceous rocks are changed in one trend (Figure 2).

Comparison of petrophysical characteristics of various degree altered effusive and clastic (tuff, tuff breccia) rocks has shown, that with increase in degree of rocks alteration up to formation propylites, argillizated rocks and secondary quartzites their properties do not change linearly. The dependence of the petrophysical properties from the degree of weathering is more complicated. Despite this, it can be seen that there is an inverse correlation between the porosity and specific electric resistivity, which is characteristic for volcanic rocks on the thermal fields of active volcanoes (see Figure 2).

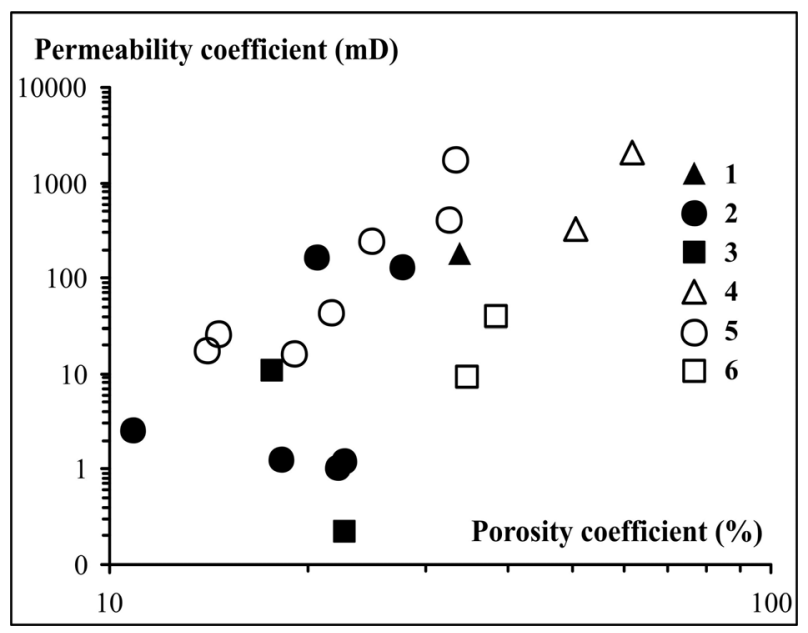

Figure 1. The permeability coefficient versus porosity coefficient for the rocks of volcanoes Ebeco (1-3) and Golovnin (4-6). 1, 4 - tuff, tuff breccia; 2 - andesites; 3, 6 - argillizated rocks; 5 - andesidacites.

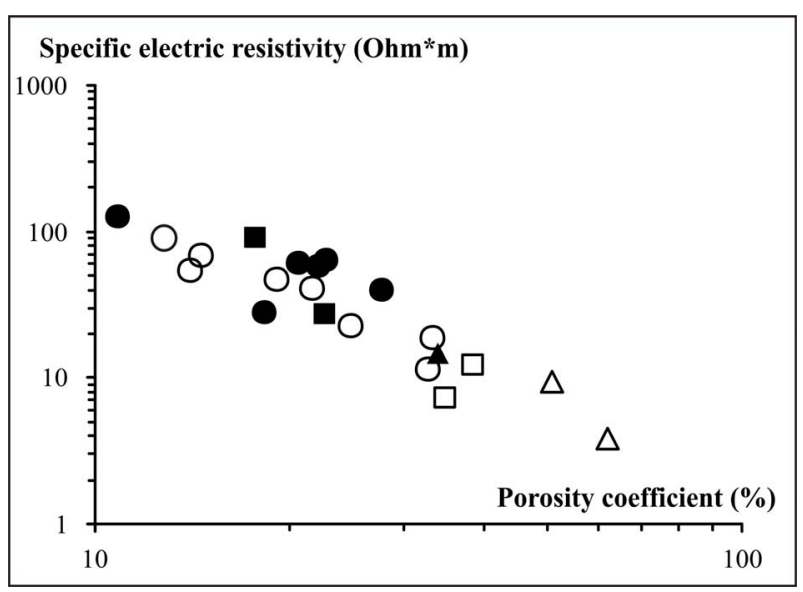

Figure 2. The specific electrical resistivity versus porosity coefficient for rocks of the volcanoes Ebeco and Golovnin. Legend look at figure 1. 
The cross sections for the North-East fumarolic field were constructed on data of the electrical resistivity tomography (Figure 3). On the figure structure of the subsurface space, the supply system of pools and fumaroles is clearly visible. Specific electric resistance of rocks in the sections is varied in the limits of $0.5-63 \mathrm{Ohm} \cdot \mathrm{m}$.

The lowest resistivity is observed in areas of fractured zones of transport of the thermal solution. The value of electrical resistivity for them is determined only by the ionic conductivity of the circulating solution and is equal to $0.43-1.4 \mathrm{Ohm} \cdot \mathrm{m}$. Increase electrical resistivity is caused, probably, with decrease in porosity of the rocks, and consequently, with their water saturation. Maximum values electrical resistivity are observed at the sites of fumarole outputs. Here the rocks are saturated with solutions in the least degree and the electrical resistivity is equal to 40-63 Ohm*m.

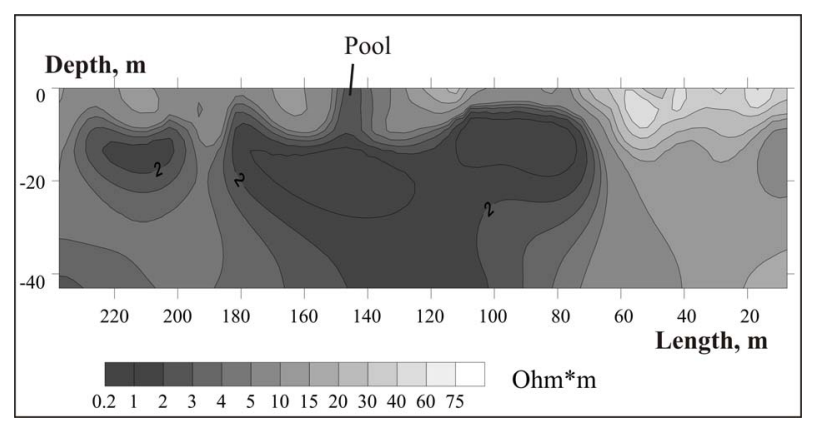

Figure 3. Geo-electrical cross sections for volcano Ebeco North-Eastern fumarolic field [7].

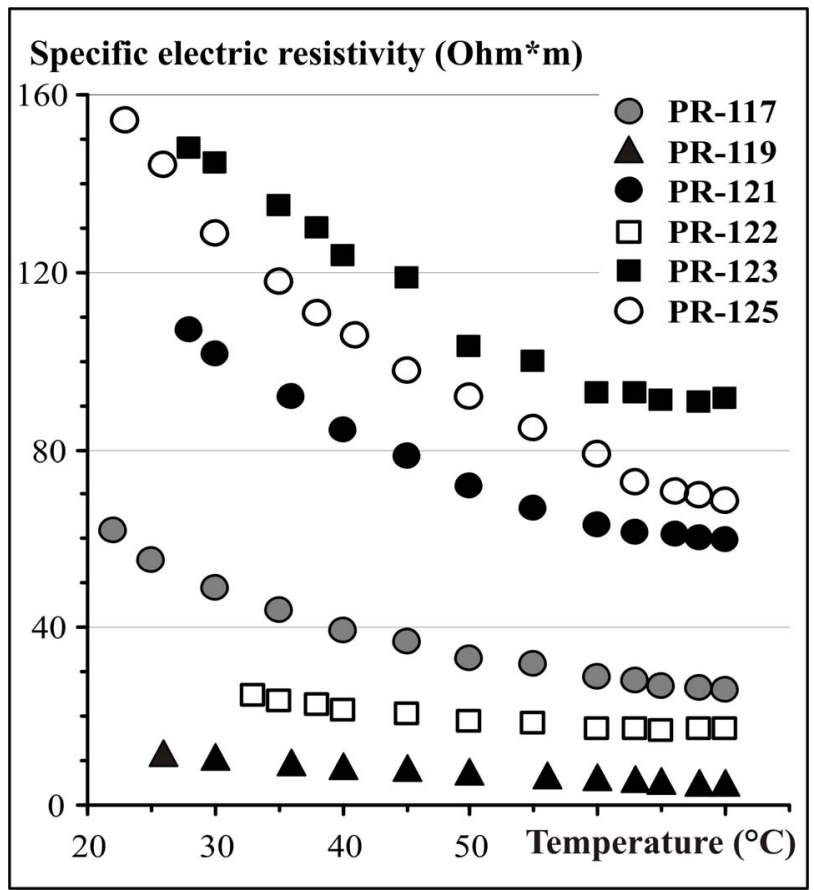

Figure 4. The specific electrical resistance versus temperature for rocks of the volcanoe Ebeco.
Comparing resistivity which was obtained with the electrical resistivity tomography and resistivity which was measured for the individual specimens, we can use other petrophysical characteristics of this sample (see Table 1) for the interpretation of the cross sections of the fumarolic field subsurface space. The decrease of the resistivity on profiles electrical resistivity tomography can be attributed to a number of factors, namely: the increase in porosity (see Figure 2); increase of mineralization of solutions which fill the pores; and increase in the temperature. In Figure 4 you can see a significant decrease of the specific electric resistance, measured in laboratory conditions, with growth of temperature. The temperature of the rocks on the surface during the sounding was equal to 29 - 46 degrees $C$, and at the depth of $1.5 \mathrm{~m}$ (in test pits) there was increase of temperature in average of 33 degrees.

\section{Conclusions}

The combination of geological, geophysical and petrophysical investigations are of great importance in the study of the structure of the subsurface space thermal fields on active volcanoes. In the interpretation of geophysical data, we can make conclusions about the composition and the texture of the rocks, which compose the cross section.

\section{Acknowledgements}

The authors thank to Professor S. B. Bortnikova, which has gathered around himself geologists of various specialties and is the inspirer of a comprehensive approach to the research of active volcanoes of the Kuril Islands, and to Deputy Director of IPGG of the SB RAS I. N. Eltsov for support at all stages of the expedition and desk works.

\section{REFERENCES}

[1] E. P. Bessonova, S. B. Bortnikova M. P. Gora, Yu. A. Manstein, A. Ya. Shevko, G. L. Panin and A. K. Manstein, "Geochemical and Geo-Electrical Study of Mud Pools at the Mutnovsky Volcano (South Kamchatka, Russia): Behavior of Elements, Structures of Feeding Channels and a Model of Origin," Applied Geochemistry, Vol. 27, No. 9, 2012, pp. 1829-1843.

[2] E. P. Bessonova, M. P. Gora, A. Ya. Shevko, K. V. Chudnenko and V. K. Cherepanova, "Estimation of Change Dynamics of Physical Characteristics of Section Hydrothermal Altered on the Nonisothermal Physico-Chemical Modeling (by the Example of the Mutnovsky)," Izvestiya, Physics of the Solid Earth, No. 6, 2011, pp. 57-68.

[3] A. Ya. Shevko, M. P. Gora, E. P. Bessonova and N. A. Golikov, "Using Petrophysical Properties of Volcanogenic Rocks for the Purposes of the Physico-Chemical 
Modeling," Modern Problems of Magmatism and Metamorphism, Materials of All-Russian Conference Devoted to the 150-anniversary of academician F. Yu. Levinson-Lessing and the 100 anniversary of Professor G. M. Sarantchina, St. Petersburg, Vol. 2, 2012, pp. 347-349.

[4] T. A. Kotenko, L. V. Kotenko, E. I. Sandimirova, V. N. Shapar' and I. F. Timofeeva, "Eruption Activity of Ebeko volcano (Papamushir I.) in 2010-2011," Bulletin of Kamchatka regional association «Educational-scientific center. Earth sciences, Vol. 19, No. 1, 2011, pp. 160-167.

[5] I. V. Melekescev, V. N. Dvigalo, V. Yu. Kirianov, A. V. Kurbatov and I. A. Nesmachnii, "Volcano Эбеко (Kuril Islands): History of Eruptive Activity and Future Volcanic Hazards. Part II," Journal of Volcanology and Seismology, No. 4, 1993, pp. 24-42.

[6] S. B. Bortnikova, E. P. Bessonova, L. B. Trofimova, T. A. Kotenko and I. V. Nikolaeva, "Hydrogeochemistry of Thermal Springs on Ebeko Volcano, Paramushir," Journal of Volcanology and Seismology, No. 1, 2006, pp.
39-51.

[7] G. L. Panin, T. A. Kotenko, L. V. Kotenko and U. G. Karin, "Geophysical and geochemical investigations of thermal fields of Ebeco volcano (Paramushir Island)," Lithosphere, No. 3, 2010, pp. 171-176.

[8] N. A. Golikov, A. Ya. Shevko, M. P. Gora and E. P. Bessonova, "Petrophisical properties of volcanogenic rocks of different degree of hydrothermal change in areas of the active volcanism (on the example of Golovnin volcano)," Interexpo Geo-Siberia-2011: 8th International specialized exhibition and scientific congress. Mineral Resources Management. Mining. New Trends and Technologies for Exploration and Prospecting of Mineral Resources, Novosibirsk, Vol. 1, 2012, pp. 183-187.

[9] J. V. Frolova, V. M. Ladygin and S. N. Rychagov, "Regularities of Transformation of Structure and Properties of Volcanogenic Rocks in Hydrothermal-Magmatic Systems of Kuril-Kamchatka Island arc," Moscow University Geology Bulletin, No. 6, 2011, pp. 52-61. 